\title{
The Glass Ionomer Cement Reinforced with Silver- Premise in Choosing the Teeth Proposed for Orthodontic Purpose Extraction
}

\author{
KAMEL EARAR ${ }^{1}$, ANCA PORUMB ${ }^{2 *}$, RUXANDRA MATEI ${ }^{2 *}$, SIMONA CAVALU ${ }^{2}$, RAMONA AMINA POPOVICl ${ }^{3}$, SERGIU FOCSANEANU ${ }^{4}$, \\ NAZEM DAWOD ${ }^{4}$, ADRIANA SACELEANU ${ }^{5}$, LIANA TODOR ${ }^{2}$ \\ 'Dunarea de J os University of Galati, Medicine and Pharmacy Faculty, Departament of Dentistry, 47 Domneasca Str., 800008,Galati, \\ Romania \\ ZUniversity of Oradea, Faculty of Medicine and Pharmacy, 10,1 Decembrie Sq., Oradea, Romania \\ 3Victor Babes University of Medicine and Pharmacy, Timisoara, Romania \\ ${ }^{4}$ University Politehnica of Bucharest, Faculty of Materials Science and Engineering, 313 Independentei Str., 060042, Bucharest, \\ Romania \\ EUniversity Lucian Blaga Sibiu, Faculty of Medicine, 2A Lucian Blaga Str., 550169, Sibiu, Romania
}

\begin{abstract}
The glass ionomer cements present very good bio compatibility especially due to the presence of Fluor in their composition. The reactivity from the dental pulp to the ionomer cements is also favorable, even in the case of the profound cavities. The metallic ionomer cements are obturation materials that tend to replace the amalgams and were created by adding of metallic alloys to the glass powder for the purpose of improving the mechanic properties. The resistance to abrasion of the glass ionomer cements reinforced with Ag is increased compared to the ionomer cements, being close to that of the composite resins with micro filling, but inferior to the amalgams or composites for the posterior area. All these properties of the metallic glass ionomers recommend their utilization in accomplishing the definitive obturations of the permanent teeth from the lateral area, where the physiognomic aspect is not on the first place and where it is necessary a material with fast grip. The physical-chemical qualities and the bio compatibility of the glass ionomers reinforced with particles of silver was our premise in their utilization for the obturation of the molars of six years in children.
\end{abstract}

Keywords: glass ionomer, cement, molar, orthodontic, dental materials

In the second half of the past century the efforts of the researchers in the field of dental materials to obtain a physiognomic material of obturation and in the same time adhesive, used for the treatment of coronaryinjuries in the frontal teeth, were materialized in obtaining the glass ionomer cements, by combining the properties of the silicate cement properties and of the poly carboxylate cement.

The glass ionomer cement is a biocomponent system: powder-liquid, with manual dose or pre-dosed in capsules. The glass ionomers, from the chemical point of view, are complex poly acrylates or glass poly alchenolates, resulted from the interaction of a watery solution of poly acrylic acid or copolymers of the acrylic acid with a fluoroalumonosilicate of calcium. The powder has as basic component element the fluoroalumonosilicate of calcium, the size of the particles influencing the final physical properties of the material. The fluorine is an essential component, stimulating the remineralization in the adjacent dental structure. The liquid was represented initially by a watery solution of poly acrylic acid, in the last period being used copolymers: the acrylic acid - the itaconic acid or the acrylic acid - maleic acid. In order to control the grip reaction is added in the liquid small quantities of tartaric acid (anhydrous systems in which the acid is liofilizated and incorporated in the powder) [13].

One of the primary objectives of the researchers from the area of dental materials, from the end of the past millennium, was that to elaborate materials of rebuilding the coronary injuries that would replace the amalgams.
The relevance of the new materials is important notjust for dental medicine [4-7], but also for other clinical specializations like orthopedics [8-11], neurosurgery [12$14]$, abdominal surgery [15-17], gynecology [18,19], cardiovascular [20-22] and ophthalmology [23].

One of the materials that entered in the composition with the amalgams is the metallic ionomer cement. The glass ionomer cement are materials used for dental obturations that tend to replace the amalgams, due to the disadvantages that they presented (color, tightness, corrosion, metallic taste), and arose by adding the metallic alloys to the glass powder for the purpose of improving the mechanical properties. In the beginning the powder represents a physical mixture between the glass and metal particles. Now the powder obtained is pressed, baked at high temperatures $\left(800^{\circ} \mathrm{C}\right)$ and is grinded, the procedure assuring the chemical binding of the metal to the glass, the atoms of metal entering in the structure of the glass. The metals used are: gold, palladium, silver and its alloys. Due to the high price of the cements with gold were replaced with silver alloys. It can be added in the powder up to $5 \%$ of titanium oxide $\left(\mathrm{TiO}_{2}\right)$ to obtain an acceptable color from the clinical, esthetic point of view. The cements amplified with metallic powders are called cermets.

Currently several materials can be considered as alternatives to amalgam in the primary dentition: conventional glass-ionomer cements, metal reinforced GIC, resin-modified GIC, cermet cements, resin composites, and polyacid-modified composites (PMC, compomers). Metal reinforced glass ionomer cements contain silver-tin alloy fibers or flakes being sintered to the 
glass particles for a better incorporation of the metal particles into the cement matrix.

\section{Experimental part}

\section{Materials and Methods}

The patient V.B., with the age of 18 , female, is presented at the orthodontics for disorders of the physiognomic function. The orthodontics diagnosis given was that of dentomaxillary disharmony with medium crowding and is decided, to create space, the performing of an extraction for orthodontic purpose. In these limit situations, in which the necessary space is not so great, between 3 and $5 \mathrm{~mm}$, the choice of the tooth or of the teeth to be extracted and of the optimum moment for extraction are problems that the orthodontics has to decide with a great perception.

The case study has considered also the fact that the interincisive centre line is deviated to the right with approximately $3 \mathrm{~mm}$. Considering the correctitude of the occlusal coronary obturations at 1.6, 2.6, 3.6'i 4.6, teeth where was also verified the correctitude of the occlusal stops, was decided the extraction of the tooth 2.5 and not the molar of six years, although it was obturated in the coronary (fig. 1).

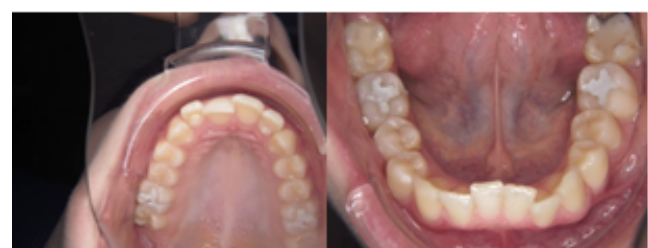

Fig. 1. The initial aspect of the upper and inferior arch, with 1.6, 2.6 3.6 and 4.6 with glass ionomers reinforced with particles of silver

From the clinical anamnesis of the patient we obtained information about the moment of performing the obturations on the level of the molars of six years, and the type of material used. Also we specify that there appeared no secondary decays on the level of the obturated molars with glass ionomers reinforced with particles of silver, the obturations having an age of 10,11 years respectively, and the molars were asymptomatic on this entire period.

From the sheet of the patient it results that the material used for the obturation of the molars of six years is Silvercem (fig. 2).

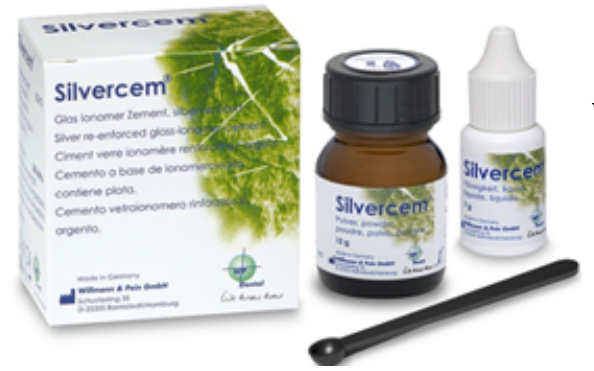

Fig.2. The glass ionomers reinforced with particles of silver used for the

obturation of the molars of six years in the patient presented in the clinical case

Also, we tested the vitality on the level of these molars, and on the orthopantomography performed can be observed the depth of the obturations (fig. 3).

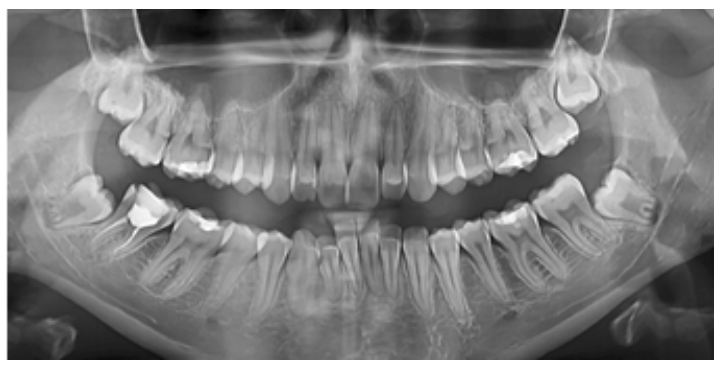

Fig. 3. Orthopantomography of the case study

\section{Results and discussions}

The orthodontic treatment was made with an upper metallic fixed polyaggregate device and lasted approximately one year. Following which all the teeth of the upper arch were enclosed harmoniously on the arch (fig. 4, 5).

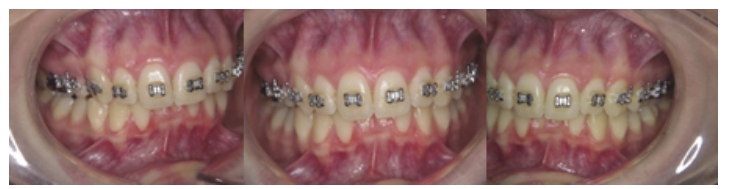

Fig. 4.The final aspect of the occlusion: front view and left-right semi profile

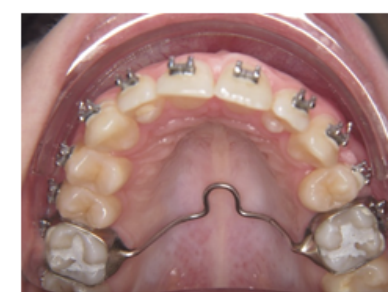

Fig.5. The aspect of the upper arch at the end of the orthodontic treatment, with molars of 6 years obturated in the occlusion with glass ionomer cement kept in the oral cavity

The glass ionomer cements present a very good biocompatibility due, especially, to the presence of fluoride in their composition. This inhibits the microbial infiltration, protecting the adjacent dental structures against the decay injury. Glass ionomer is a real tank of fluoride on the entire period of life of the restoration. The reactivity from the dental pulp to the ionomer cements is favorable, even in the case of the profound cavities. The fluoride release of conventional glass ionomer cements is estimated higher compared with light-curing glass ionomer cements and compomers. Especially in young children the fluoride release may not only help to prevent secondary caries around the filling but may also reduce the risk of caries at the surface of the adjacent tooth [24-26].

The glass ionomer cements adhere chemically to the enamel, dentine, plaster and metals covered with a superficial layer of oxides. They adhere to ceramics and noble metals. The mechanism of the adhesion has at its basis the phenomenon of diffusion and that of absorption, which will give a very strong adhesion between the two sub layers [15]. The clinical studies showed that in case of a failure of a restoration with a glass ionomer it takes place the cracking of the obturation but maintaining a layer of cement adherent to the dental rough structures. The adhesion is better after the conditioning of the dental surfaces with a watery solution of polyacrylic acid $[1,3,4]$.

From the desire to improve the properties of the classic ionomer cements they hybrid materials appeared, which are strengthen by combining the reaction of gripping acidalkali with photo chemical polymerization. Thus is obtained an immediate resistance to the absorption of water and the protection against the dehydration. The resistance to fracture is almost doubled, being almost as resistant as the composite resins with micro filling.

The mechanical resistance of the glass ionomers is larger than of the zinc phosphate and zinc polycarboxylate cements. The hardness increases with the proportion of the powder, but also during the maturing of the obturation. Still their resistance to fracturing is decreased compared to that of the amalgams or composite resins, which limits their utilization in the areas of occlusal stress. The metal particles improve the mechanical properties of the cements and increase their wear resistance. 
The resistance to abrasion of the ionomer cements reinforced with silver is increased compared to the ionomer cements, being close to that of the composite resins with micro filling, but inferior to the amalgams or composites for the posterior area.

The resistance to fracturing remains decreased because the module of elasticity of the cement remains decreased (table 1) [26].

Table 1

THE LOSS OF SUBSTANCE BY SIMULATED ABRASION AT THE SURFACE OF AN OCCLUSAL OBTURATION

\begin{tabular}{|c||c|}
\hline Material of obturation & Losses $\left(\mathrm{mm}^{3}\right)$ \\
\hline \hline Amalgams & 0.2 \\
\hline Composites with micro filling & 0.2 \\
\hline Metallic Ionomer Cements (Ag) & 0.3 \\
\hline Conventional composites & 0.4 \\
\hline Ionomer Cements & 6.0 \\
\hline
\end{tabular}

Cermet ionomer cements are sintered metal/glass powders, which can be made to react with poly(acids). These new cements are significantly more resistant to abrasion than regular glass ionomer cements and are widely accepted as core build-up materials and lining cements. They can strengthen teeth and provide the clinician with an opportunity to treat early dental caries [27].

Further development of glass ionomer cements focused on a higher powder-to-liquid ratio, a lower water content, and smaller glass particles leading to high viscosity glass ionomer cements, which should be packable like amalgam and reveal enhanced flexural strength characteristics [27].

Due to the amalgam-like optical performance, metalreinforced materials showed an enormous commercial success and were consequently used as posterior materials for the primary dentition as well. Primarily in uncooperative children this group of restorative materials exhibits advantageous handling properties [28].

Glass ionomer cements are influenced by different $\mathrm{pH}$ saliva $[29,30]$. As long as the material is tolerated and protected by the tooth structure, resistance to abrasion will be satisfying $[1,4]$. Selection of restorative materials must be based on knowledge of their wear behavior and the individual needs of each patient $[27,30]$. The resistance depends on the inherent properties of the material [15, 30].

Anti-cariogenic properties such as long-term fluoride release, antibacterial properties, biocompatibility, and low thermal expansion are advantages that support the valuable position of these materials in daily dental practice $[24,31]$.

\section{Conclusions}

The properties of the glass ionomers recommend them to be used in the performance of definitive obturations in the young permanent teeth from the lateral area, where the physiognomic aspect is not prioritary and where it is necessary a material with fast grip. Still is recommended to be used with care in the areas of maximum occlusal stress.

The physical-chemical qualities, the absence of the secondary decays and the bio compatibility of the glass ionomers reinforced with particles of silver was our premise in their utilization in the obturation of the molars of six years in children, as an alternative to the composite materials.

\section{References}

1.BERESCU F.G., HANCU V., MUCENIC S.G, COSARCA A.S, COMANEANU R.M, ORMENISAN A., Mat. Plast., 52(2), 2015, p.272-278

2.BALAN, A., SAVIN, C., SANDU, A.V., et al., Mat. Plast., 53, no.1, 2016, p.100-104.

3.BARLEAN, L., COMAN, M., BOBU, L., et al., Mat. Plast., 52, no.4, 2015, p.542-546

4.EARAR, K., ANTONIAC, I., BACIU, S., et al., Rev. Chim. (Bucharest), 68, no.11, 2017, p. 2700-2703

5.RAU J.V., ANTONIAC I., et al., Materials Science and Engineering C, 64, 2016, p. 362-369.

6.CRACIUNESCU E., SINESCU C., NEGRUTIU M.L., et al., J Adhes Sci Technol., 30(6), 2016, p.666-676.

7.BITA I., STAN G., NICULESCU M., et al., J Adhes Sci Technol., 30(18), 2016, p. 1968-1983.

8.ANTONIAC I., NEGRUSOIU M., MARDARE M., et al., Medicine. 96(19):e6687, 2017.

9.MARINESCU, R., ANTONIAC, I., LAPTOIU, D., et al, Mat. Plast., 52, no.4, 2015, p. 340-344.

10.GRECU, D., ANTONIAC, I., TRANTE, O., et al., Mat. Plast., 53, no.4, 2016, p.776-780.

11.BENEA H., TOMOAIA G., SORITAU O., et al., Romanian Biotechnological Letters, 21(4), 2016, p.11720-11728.

12.VOINESCU D.C., MOHAN A.G., MARINESCU A.A., CIUREA A.V., Romanian J ournal of Morphology and Embriology, 58(1), 2017, p.297300.

13.RIVIS, M., PRICOP, M., TALPOS, S., et al., Rev. Chim. (Bucharest), 69, no.4, 2018, p.990-993.

14.CAVALU, S., EARAR, K., LASLO, V., et al., Rev. Chim (Bucharest), 68, no.12, 2017, p.2963-2966.

15.ANTONIAC I., SINESCU C., ANTONIAC A., J Adhes Sci Technol., 30(16), 2016, p.1711-1715.

16.PARIZA, G., MAVRODIN, C.I., ANTONIAC, I., Mat. Plast., 52, no.4, 2015, p.484-486.

17.EARAR, K., GRADINARU, S., PARIZA, G. et al., Rev. Chim. (Bucharest), 68, no.8, 2017, p. 1868-1873.

18.BRATILA E., COMANDASU D., MILEA C. et al., J Adhes Sci Technol., 31(18), 2017, p.2028-2043.

19.CIRSTOIU, M., CIRSTOIU, C., ANTONIAC, I., MUNTEANU, O., Mat. Plast., 52, no.2, 2015, p. 258-262

20.JURCUT R., SAVU O., Popescu B., et al., Circulation, 121(21), 2010, p.E415-E418.

21.IOSIFESCU A.G., MOLDOVAN H., ILIESCU V.A., J ournal of Hearth Valve Disease, 23(2), 2014, p.149-157.

22.COSTACHE V., MOLDOVAN H., ARSENESCU C., et al., Minerva Cardioangiologica, 66(2), 2018, p.191-197.

23.ANTONIAC, I., BURCEA, M., IONESCU, R.D., BALTA, F., Mat. Plast., 52, no.1, 2015, p.109-112.

24.GLASSPOOLE E.A., ERICKSON R.L., DAVIDSON C.L., Dent Mater., 18, no.6, 2002, p.454

25.REKHA VISHNU, C., BALOGOPAL VARMA, JAYANTHI, Contemporary Clinical Dentistry, 3, no.3, 2012, p 282

26.CHADWICH B.L., EVANS D.J.P., European Academy of Paediatric Dentistry ISSN:1818-6300, 8(1), 2007, p. 100-120.

27.BRATU D., CIOSESCU D., ROMINU M., et al., Dental Materials, vol II, Materials used the in dentistry medical practice. Ed. Helicon Banat SA, Timisoara, 1994, p.139-150.

28.HICKEL R., MANHART J., J Adhesive Dent, 3(1), 2001, p.45-64.

29.KRAMER N., FRANKERBERGER R., British Dental Journal, 190(6), 2001, p.317-321.

30.YIP K.H., SMALESR.J ., KAIDONISJ .A., Int] Prosthodont, 2004, 17(3), p.350-356.

31.HANGANU, S.C, ARMENICA, A.O., MURARIU, A.M., et. Al., Mat Plast, 50, no.3, 2013, p 192-196.

$\overline{\text { Manuscript received:22.07.2018 }}$ 